Rev. Adm. Saúde Vol. 17, № 69, Out. - Dez. 2017

http://dx.doi.org/10.23973/ras.69.59

ARTIGO DE REVISÃO

\title{
Competências do enfermeiro na gestão do cuidado
}

Nursing skills in care management

\section{Patrícia Treviso', Sabrina Capeletti Peres², Alessandra Dartora da Silva ${ }^{3}$, Adriana Alves dos Santos ${ }^{4}$}

1. Enfermeira, doutora em educação. Professora do Departamento de Enfermagem da Universidade Federal de Ciências da Saúde de Porto Alegre e do Centro Universitário Metodista IPA, Porto Alegre/RS

2. Enfermeira da Universidade Federal de Ciências da Saúde de Porto Alegre e do Centro Universitário Metodista IPA, Porto Alegre/RS

3. Enfermeira, doutora em educação. Professora do Departamento de Enfermagem da Universidade Federal de Ciências da Saúde de Porto Alegre e do Centro Universitário Metodista IPA, Porto Alegre/RS

4. Enfermeira, mestre em biociências e reabilitação. Professora do Curso de Enfermagem do Centro Universitário Metodista IPA, Porto Alegre/RS

\section{RESUMO}

Para o gerenciamento do cuidado, o enfermeiro deve desenvolver competências mediante a utilização de ferramentas, que seriam facilitadores do processo de trabalho. Com o objetivo de conhecer as competências necessárias para o enfermeiro atuar nas diversas áreas profissionais e identificar as ferramentas utilizadas nesse processo, realizou-se uma revisão integrativa. A coleta de dados ocorreu nas bases de dados BDEnf, LiLACS e SciELO, conforme o período delimitado entre os anos de 2009 e 2013, totalizando 12 artigos, após o cruzamento dos descritores e seguindo os critérios de inclusão e exclusão. Foram identificadas duas categorias: ferramentas de processos gerenciais e desafios a percorrer no âmbito da gestão em enfermagem. Para o aperfeiçoamento e a qualificação do processo de trabalho, a atuação do enfermeiro deve ser pautada nas competências profissional e gerencial desenvolvidas por ele, aliando assistência, 
gerenciamento e desenvolvendo na prática o conhecimento adquirido durante sua formação e qualificação.

Palavras-chave: enfermagem, educação em enfermagem, competência profissional, gerência, liderança, comunicação em saúde.

\begin{abstract}
For care management, nurses should develop skills through the use of tools, which would be facilitators of the working process. This study is exploratory and descriptive, contemplating a qualitative approach through a literature review. In order to meet the skills required for nurses in different areas and identify the instruments/tools used in the process. Data collection occurred in the database BDEnf, LiLACS and SciELO, as delimited period between 2009 and 2013, totaling 12 articles after matching the descriptors and following the inclusion and exclusion criteria. Integrative review, identified two categories: tools of management processes and challenges to go in nursing management. For the improvement and qualification of the work process, the work of nurses must be based on professional and managerial skills developed by him, combining care and management by applying in practice the knowledge acquired during their training and qualification.
\end{abstract}

Keywords: nursing, nursing education, professional competence, management, leadership, health communication.

\title{
INTRODUÇÃO
}

O processo de trabalho do enfermeiro permeia as esferas gerencial e assistencial, perpassando o ensino e a pesquisa, que estão diretamente ligados às práticas do cuidado, tornando-o, dessa forma, um gerenciador do cuidado. Isto requer competências dos profissionais. A competência é definida como a capacidade de articular valores, conhecimentos, habilidades e atitudes necessários para o desempenho eficaz de atividades requeridas pela natureza do trabalho, além do alcance dos objetivos estabelecidos ${ }^{(1-2)}$.

As competências são consideradas elementos indispensáveis para o gerenciamento do cuidado, principalmente em um contexto em que "as mudanças tecnológicas solicitam, cada vez mais, o conhecimento especializado, exigindo do profissional capacidade de pensar, agir, interagir e decidir em um sistema complexo de informações e comunicação, usando a tecnologia de modo inteligente"(3:49). São ainda necessárias competências, tais como: tomada de decisões, comunicação, liderança, administração, gerenciamento e educação permanente ${ }^{(4)}$. A incorporação e o estímulo ao 
desenvolvimento de competências e habilidades na formação profissional estão referidos nas Diretrizes Curriculares Nacionais (DNCS) ${ }^{(5)}$, que as apontam como aliadas no exercício profissional, desde o planejamento das ações nos serviços até a prática da gerência do cuidado, propondo, assim, um novo perfil profissional na área da saúde(6). Nesse contexto, as DCNs buscam aproximar a realidade do serviço e a formação dos profissionais, com base nas definições de competências, traduzidas em conhecimentos, habilidades e atitudes que possibilitam uma melhor atuação do enfermeiro, respondendo às necessidades do profissional, da instituição e dos sujeitos ${ }^{(4-5)}$.

A busca pela construção do conhecimento e melhores práticas assistenciais mobiliza a interação entre as pessoas envolvidas, articulando, assim, toda a rede de saúde, onde a prática gerencial do enfermeiro envolve múltiplas ações de gerenciar cuidando e educando, de cuidar gerenciando e educando, de educar cuidando e gerenciando ${ }^{(7)}$. Um grande desafio em âmbito gerencial se dá pela deficiência de investimento em políticas de recursos humanos, além da transformação necessária da forma de repensar no papel da universidade na formação de profissionais para atuação no mercado de trabalho ${ }^{(8)}$.

Esse descompasso entre o processo de formação e a prática na enfermagem resulta em tensões, desmotivação e conflitos. A preocupação das escolas tem sido a preparação dos profissionais para a realização de um cuidado individualizado altamente qualificado, o que muitas vezes não é o único objetivo das instituições, sendo exigidas do profissional ações de gerência de serviços e pessoas, o que, não raro, se limita ao controle de material e de pessoal, em detrimento do gerenciamento do cuidado ${ }^{(9)}$.

Entre tantas competências necessárias ao enfermeiro, destaca-se a liderança, pois permite ao profissional enfermeiro condições de desenvolver um bom gerenciamento e qualificar a assistência prestada. A liderança advém de uma boa comunicação, pois possibilita a aproximação da equipe, a compreensão das atividades executadas, um melhor planejamento do trabalho, bem como criação de interdependências para o desenvolvimento do trabalho por meio da equipe multidisciplinar ${ }^{(10)}$.

Assim, o enfermeiro emerge historicamente como um profissional que tem competência e atuação na gerência do cuidado prestado pela equipe de enfermagem. No entanto, em alguns espaços, a atuação do enfermeiro parece sofrer influência de políticas e de diversos modelos de trabalho propostos pelas instituições de saúde. Diante disto, questiona-se: como se desenvolvem e quais competências são necessárias para uma efetiva atuação do enfermeiro no gerenciamento do cuidado?

\section{MÉTODO}

Trata-se de um estudo de revisão integrativa de literatura. A revisão integrativa propõe o estabelecimento de critérios bem definidos quanto à coleta de dados, análise e interpretação dos resultados. Seis etapas foram adotadas para a realização deste estudo: 1) seleção da questão de pesquisa; 2) definição dos 
critérios de inclusão e exclusão e determinação da amostra; 3) representação dos estudos selecionados em formato de tabelas, considerando todas as características em comum; 4) análise crítica dos resultados, identificando diferenças e conflitos; 5) interpretação dos dados; e 6) relato, de forma clara, da evidência encontrada.

A estratégia de identificação e seleção dos estudos fundamentou-se em publicações indexadas na base de dados da Biblioteca Virtual de Saúde (BVS), na Literatura Latino-Americana e do Caribe em Ciências da Saúde (LiLACS), na Base de Dados Bibliográficos Especializada na Área de Enfermagem do Brasil (BDEnf) e no Scientific Electronic Library Online (SciELO), consideradas como as principais bases de dados das ciências da saúde em geral e enfermagem brasileira.

Foram adotados os seguintes critérios de inclusão: artigos publicados em português, disponíveis na íntegra, de 2009 a 2013, relacionados ao problema de pesquisa. Excluíram-se artigos incompletos, artigos de revisão, artigos em outra língua, teses, dissertações e livros ou os que não tinham relação com o objetivo proposto.

A busca das informações nas bases de dados ocorreu a partir dos descritores classificados nos Descritores em Ciências da Saúde (DeCS): enfermagem, educação em enfermagem, competência profissional, gerência, liderança e comunicação em saúde.

Após identificação nas bases de dados, seleção dos artigos considerando os critérios de exclusão e inclusão e cruzamento entre os descritores, procedeu-se à delimitação do corpus de análise pela relação do artigo com o problema e os objetivos de pesquisa a partir da análise do título e do resumo. Pelas exclusões descritas acima, este trabalho tem seu corpus de análise constituído por 12 artigos.

A coleta de dados foi realizada mediante consulta à base de dados. Os dados foram então organizados em uma planilha, constando: tema de análises, descritor, ano e local de publicação, título, objetivos, metodologia, base de dados e participantes.

Os artigos foram rigorosamente referenciados, sendo respeitadas as ideias dos autores, conforme previsto na Lei o 9.610/98, Lei do Direito Autoral(11), que determina que pertença ao autor os direitos morais e patrimoniais sobre a obra que criou, assim como foi respeitado o direito de ter seu nome, pseudônimo ou sinal convencional indicado ou anunciado como sendo o do autor, na utilização de sua obra. Também foi assegurada a integridade da obra, opondo-se a quaisquer modificações ou à prática de atos que, de qualquer forma, possam prejudicá-la ou atingir o autor em sua reputação ou honra, conforme normas da ABNT.

\section{RESULTADOS E DISCUSSÃO}


O corpus de análise da pesquisa foi constituído por 12 artigos publicados no período de 2009 a 2013. Destes artigos, evidenciou-se a BDEnf como a base de dados com mais publicações sobre o tema ( $50 \%)$, seguida de SciELO $(41,6 \%)$ e LiLACS $(8,3 \%)$. O maior número de publicações ocorreu nos anos de 2009 e 2011. Quanto à distribuição dos artigos por região, a região sul apresentou $50 \%$ das publicações; a sudeste, $33,3 \%$; e as regiões nortenordeste, $16,6 \%$. Acredita-se que essa variação de locais de publicações ocorra devido ao número de cursos oferecidos nessas regiões. "[...] o eixo SulSudeste representa $71,2 \%$ do universo de cursos de Graduação em

Enfermagem do Brasil. Nestas regiões, destacam-se os estados de São Paulo, Rio de Janeiro, Minas Gerais e Paraná, com o maior número de cursos"(12:104).

No que se refere às metodologias utilizadas, observa-se o predomínio da abordagem exploratório-qualitativa (50\%), seguida da abordagem qualitativa do tipo estudo de caso $(16,7 \%)$ e de reflexão $(25 \%)$; já a metodologia exploratória transversal quantitativa foi pouco utilizada $(8,3 \%)$. Quatro pesquisas foram realizadas em hospitais, quatro em universidades com professores e/ou graduandos, uma com profissionais de unidade básica, uma com profissionais de uma empresa, e três estavam relacionadas com instituições de ensino.

Em relação aos participantes dos estudos, docentes do curso de enfermagem apareceram em quatro artigos, enquanto pós-graduandos do curso de enfermagem participaram em duas publicações; nas outras seis publicações, os participantes foram enfermeiros, sendo a maioria do sexo feminino. Este último dado se deve ao fato de as primeiras atividades relacionadas à enfermagem terem estado sob a tutela das mulheres. Com a profissionalização da enfermagem, passou-se a perceber a presença masculina, mas ainda em pequena escala. No contexto da saúde, por conta de construções culturais que vinculam o cuidado às atribuições femininas, é possível perceber as representações sociais existentes sobre o profissional enfermeiro e justifica-se, portanto, a frequência do sexo feminino nesta profissão ${ }^{(13)}$.

Quadro 1. Síntese dos artigos selecionados, de acordo com ano, autor(es), título, publicação e categoria.

\begin{tabular}{|l|l|l|l|l|}
\hline Artigo & Autores & Título & Publicação & Categoria \\
\hline Ano $11^{(14)}$ & $\begin{array}{l}\text { Rothbarth S, } \\
\text { Wolff LDG, } \\
2009\end{array}$ & $\begin{array}{l}\text { O desenvolvimento de } \\
\text { competências gerenciais } \\
\text { do enfermeiro na } \\
\text { perspectiva de docentes } \\
\text { de disciplinas de } \\
\text { Administração aplicada à } \\
\text { Enfermagem }\end{array}$ & $\begin{array}{l}\text { Texto } \\
\text { Contexto } \\
\text { Enfermagem }\end{array}$ & $\begin{array}{l}\text { Ferramentas de } \\
\text { processos } \\
\text { gerenciais }\end{array}$ \\
\hline
\end{tabular}




\begin{tabular}{|c|c|c|c|c|}
\hline $\bar{A} 2^{(15)}$ & $\begin{array}{l}\text { Gelbcke FL, } \\
\text { Souza LA, } \\
\text { Sasso GM, } \\
\text { Nascimento E, } \\
\text { Bulb MBC }\end{array}$ & $\begin{array}{l}\text { Liderança em ambientes } \\
\text { de cuidados críticos: } \\
\text { reflexões e desafios à } \\
\text { Enfermagem Brasileira }\end{array}$ & $\begin{array}{l}\text { Revista } \\
\text { Brasileira de } \\
\text { Enfermagem }\end{array}$ & $\begin{array}{l}\text { Ferramentas de } \\
\text { processos } \\
\text { gerenciais. } \\
\text { Desafios a } \\
\text { percorrer no } \\
\text { âmbito da gestão } \\
\text { em enfermagem }\end{array}$ \\
\hline $\begin{array}{l}\mathrm{A} 3^{(16)} \\
2009\end{array}$ & $\begin{array}{l}\text { Hausmann M, } \\
\text { Peduzzi M. }\end{array}$ & $\begin{array}{l}\text { Articulação entre as } \\
\text { dimensões gerencial e } \\
\text { assistencial do processo } \\
\text { de trabalho do } \\
\text { enfermeiro }\end{array}$ & $\begin{array}{l}\text { Texto } \\
\text { Contexto } \\
\text { Enfermagem }\end{array}$ & $\begin{array}{l}\text { Ferramentas de } \\
\text { processos } \\
\text { gerenciais }\end{array}$ \\
\hline $\begin{array}{l}\mathrm{A} 4^{(17)} \\
2009\end{array}$ & $\begin{array}{l}\text { Fernandes LCL, } \\
\text { Machado RZ, } \\
\text { Anschau GO }\end{array}$ & $\begin{array}{l}\text { Gerência de serviços de } \\
\text { saúde: competências } \\
\text { desenvolvidas e } \\
\text { dificuldades encontradas } \\
\text { na atenção básica }\end{array}$ & $\begin{array}{l}\text { Ciência \& } \\
\text { Saúde } \\
\text { Coletiva }\end{array}$ & $\begin{array}{l}\text { Ferramentas de } \\
\text { processos } \\
\text { gerenciais. } \\
\text { Desafios a } \\
\text { percorrer no } \\
\text { âmbito da gestão } \\
\text { em enfermagem }\end{array}$ \\
\hline $\begin{array}{l}A 5^{(18)} \\
2010\end{array}$ & $\begin{array}{l}\text { Vilela PF, } \\
\text { Souza AC }\end{array}$ & $\begin{array}{l}\text { Liderança: um desafio } \\
\text { para o enfermeiro } \\
\text { recém-formado }\end{array}$ & $\begin{array}{l}\text { Revista } \\
\text { Enfermagem } \\
\text { UERJ }\end{array}$ & $\begin{array}{l}\text { Ferramentas de } \\
\text { processos } \\
\text { gerenciais }\end{array}$ \\
\hline $\begin{array}{l}\mathrm{A} 6^{(19)} \\
2010\end{array}$ & $\begin{array}{l}\text { Pitthan LO, Guido } \\
\text { LA, } \\
\text { Linch GFC. }\end{array}$ & $\begin{array}{l}\text { Reflexão acerca da } \\
\text { gerência em } \\
\text { enfermagem: somos } \\
\text { todos competentes }\end{array}$ & $\begin{array}{l}\text { Revista } \\
\text { Enfermagem } \\
\text { UFPE }\end{array}$ & $\begin{array}{l}\text { Ferramentas de } \\
\text { processos } \\
\text { gerenciais }\end{array}$ \\
\hline $\begin{array}{l}A 7^{(20)} \\
2011\end{array}$ & $\begin{array}{l}\text { Santos JLG, } \\
\text { Prochnow AG, } \\
\text { Lima SBS, Leite } \\
\text { JL, } \\
\text { Erdmann AL. }\end{array}$ & $\begin{array}{l}\text { Concepções de } \\
\text { comunicação na } \\
\text { Gerência de } \\
\text { Enfermagem Hospitalar } \\
\text { entre enfermeiros } \\
\text { gerentes de um Hospital } \\
\text { Universitário }\end{array}$ & $\begin{array}{l}\text { Revista } \\
\text { Escola de } \\
\text { Enfermagem } \\
\text { USP }\end{array}$ & $\begin{array}{l}\text { Ferramentas de } \\
\text { processos } \\
\text { gerenciais. } \\
\text { Desafios a } \\
\text { percorrer no } \\
\text { âmbito da gestão } \\
\text { em enfermagem }\end{array}$ \\
\hline $\begin{array}{l}\mathrm{A} 8^{(21)} \\
2011\end{array}$ & $\begin{array}{l}\text { Almeida ML, } \\
\text { Segui MLH } \\
\text { Maftum MA, } \\
\text { Labronici LM, } \\
\text { Peres AM }\end{array}$ & $\begin{array}{l}\text { Instrumentos gerenciais } \\
\text { utilizados na tomada de } \\
\text { decisão do enfermeiro } \\
\text { no contexto hospitalar }\end{array}$ & $\begin{array}{l}\text { Texto } \\
\text { Contexto } \\
\text { Enfermagem }\end{array}$ & $\begin{array}{l}\text { Ferramentas de } \\
\text { processos } \\
\text { gerenciais }\end{array}$ \\
\hline $\begin{array}{l}\mathrm{A9}^{(22)} \\
2011\end{array}$ & $\begin{array}{l}\text { Santos JLG, Lima } \\
\text { MADS }\end{array}$ & $\begin{array}{l}\text { Gerenciamento do } \\
\text { cuidado: ações dos } \\
\text { enfermeiros em um } \\
\text { serviço hospitalar de } \\
\text { emergência }\end{array}$ & $\begin{array}{l}\text { Revista } \\
\text { Gaúcha } \\
\text { Enfermagem }\end{array}$ & $\begin{array}{l}\text { Ferramentas de } \\
\text { processos } \\
\text { gerenciais }\end{array}$ \\
\hline $\begin{array}{l}\mathrm{A} 10^{(23)} \\
2012\end{array}$ & $\begin{array}{l}\text { Guedes CCP, } \\
\text { Aguiar BGC }\end{array}$ & $\begin{array}{l}\text { Discutindo e refletindo } \\
\text { sobre a competência do } \\
\text { Enfermeiro offshore }\end{array}$ & $\begin{array}{l}\text { Revista } \\
\text { Enfermagem } \\
\text { UERJ }\end{array}$ & $\begin{array}{l}\text { Ferramentas de } \\
\text { processos } \\
\text { gerenciais }\end{array}$ \\
\hline
\end{tabular}




\begin{tabular}{|l|l|l|l|l|}
\hline A11(24) & $\begin{array}{l}\text { Okagawa FS, } \\
\text { Bohomol E, } \\
\text { Cunha ICKO }\end{array}$ & $\begin{array}{l}\text { Competências } \\
\text { desenvolvidas em um } \\
\text { curso de especialização } \\
\text { em gestão em } \\
\text { enfermagem à distância }\end{array}$ & $\begin{array}{l}\text { Acta Paulista } \\
\text { de } \\
\text { Enfermagem }\end{array}$ & $\begin{array}{l}\text { Ferramentas de } \\
\text { processos } \\
\text { gerenciais }\end{array}$ \\
\hline A12(25) & $\begin{array}{l}\text { Caveião C, Hey } \\
\text { AP, }\end{array}$ & $\begin{array}{l}\text { Administração em } \\
\text { enfermagem: um olhar } \\
\text { na perspectiva do } \\
\text { pensamento complexo }\end{array}$ & $\begin{array}{l}\text { Revista de } \\
\text { Enfermagem } \\
\text { UFSM }\end{array}$ & $\begin{array}{l}\text { Ferramentas de } \\
\text { processos } \\
\text { gerenciais. } \\
\text { Desafios a } \\
\text { percorrer no } \\
\text { âmbito da gestão } \\
\text { em enfermagem }\end{array}$ \\
\hline
\end{tabular}

Com a finalidade de melhor discutir as publicações, os dados foram agrupados em duas categorias: a) ferramentas de processos gerenciais e b) desafios a percorrer no âmbito da gestão em enfermagem. A seguir são descritas as categorias desta pesquisa.

\section{Ferramentas de processos gerenciais}

Historicamente, a enfermagem caminha pela assistência e pela administração como se fossem duas dimensões paralelas. Essa dicotomia evidencia-se por meio de um processo de trabalho fragmentado, que distingue o cuidado direto, centrado na assistência, do cuidado indireto, que tem como foco a esfera gerencial. A articulação das esferas gerencial e assistencial, com a comunicação e interação com os usuários, configura o gerenciamento do cuidado. Isso faz com que o enfermeiro, com o objetivo de reduzir essa dicotomia, articule essas esferas mediante o desenvolvimento de competências específicas.

Para o desenvolvimento de competências, surgem as Diretrizes Curriculares Nacionais, que orientam que, em cada espaço, é preciso que o profissional de saúde desempenhe atividades ancoradas em suas competências essenciais, para guiá-los em transformações e adequações sem perderem o objetivo da assistência à saúde $\left(A 6^{(19)}\right)$. Os autores definem competência como o saber agir responsável em cada situação concreta, que agrega valor social ao indivíduo e valor econômico para a organização $\left(A 6^{(19)}\right)$. Além do desenvolvimento de competências, há necessidade de fundamentação para o melhor desempenho das atividades do enfermeiro $\left(A 3^{(16)}, A 4^{(17)}, A 8^{(21)}\right)$.

O cenário da saúde vem sofrendo transformações. Há novos espaços de reflexão acerca da competência profissional, para que, por meio da identificação e do desenvolvimento das competências, se modifique a atuação dos profissionais nos serviços de saúde, visando ao aprimoramento e à qualificação da assistência, de modo que o enfermeiro se coloque como elo entre as diferentes esferas do processo de trabalho $\left(A 1^{(14)}\right)$. 
A competência gerencial do enfermeiro consiste em saber articular e integrar ações, favorecendo, qualificando e contextualizando a assistência, de forma previsível ou planejada, enquanto a competência profissional deve emergir em toda e qualquer situação, seja ela previsível ou não. Além disso, o profissional enfermeiro tem o papel de planejar, coordenar, direcionar e avaliar o processo de trabalho da equipe de enfermagem $\left(\mathrm{A} 1^{(14)}\right)$.

Programas de desenvolvimento pessoal e profissional, bem como cursos de aperfeiçoamento, são algumas das ferramentas para desenvolver as competências gerenciais necessárias $\left(\mathrm{A} 1^{(14)}\right)$. A flexibilidade do sujeito e sua capacidade de adaptação a mudanças são fundamentais para que o profissional se mantenha competente.

A competência gerencial em um ambiente específico, offshore, em plataformas de petróleo, parece ser de interesse não só do profissional, mas também da instituição, pois o profissional entende que as necessidades dos serviços vão além daquelas inerentes à sua função, incluindo gerenciar, cuidar, administrar, ensinar e orientar $\left(\mathrm{A} 10^{(23)}\right)$.

Algumas ferramentas são necessárias para o desenvolvimento das competências gerenciais, tais como liderança, comunicação e tomada de decisão, entre outras que qualificam o processo de trabalho do enfermeiro. Agregadas à sua essência e interação com os outros, auxiliam a orientar novas condutas e modificar processos.

As ferramentas gerenciais são definidas como estratégias e ações utilizadas para o alcance de um objetivo comum. Mesmo de forma empírica e sem reflexão, são usadas na tomada de decisões dos enfermeiros (A8 ${ }^{(21: 133)}$ ).

Dos artigos analisados, cinco citam a comunicação como ferramenta do exercício gerencial do enfermeiro. Destacam-se dois tipos distintos de comunicação: a primeira, relacionada à perspectiva dialógica e interativa; a outra, formal, é pautada na transmissão e manutenção de informações e rotinas do serviço de forma hierárquica $\left(A 7^{(20)}\right)$. Destacam-se, ainda, a comunicação escrita como a mais utilizada no gerenciamento de enfermagem, seguida da comunicação oral, usada de forma estratégica para uma rápida transmissão da mensagem $\left(A 7^{(20)}\right)$. Entretanto, os artigos foram unânimes em apontar que a comunicação é fundamental para a gerência do cuidado, aproximando as ações da equipe de profissionais em busca do planejamento e no alcance dos objetivos, sendo uma das suas principais ferramentas de trabalho.

No estudo realizado em diferentes regiões do Brasil, a comunicação surge como segunda competência de gestão, ficando atrás somente da liderança $\left(\mathrm{A} 11^{(24)}\right)$. A comunicação interfere também na liderança da enfermeira, pois é a base para essa prática; comunicação e liderança são indispensáveis para a resolução de conflitos. A comunicação é ressaltada como habilidade necessária para o exercício da liderança $\left(\mathrm{A} 2^{(15)}, \mathrm{A} 5^{(18)}\right)$. O enfermeiro líder é aquele que articula diferentes serviços e profissionais, sendo referência por intermédio do apoio à sua equipe, além de distribuir o processo de trabalho, corresponsabilizando todos os envolvidos $\left(A 2^{(15)}, A 5^{(18)}\right)$. 
A liderança é ressaltada nas pesquisas realizadas como sendo um instrumento presente em todas as atividades desenvolvidas pelo enfermeiro, independentemente do estilo gerencial que este apresente, sendo inerente ao seu trabalho. A liderança na enfermagem atual é a principal ferramenta no processo de trabalho do enfermeiro $\left(A 8^{(21)}, A 9^{(22)}\right)$. Entretanto, alguns desafios são encontrados no exercício da liderança: aceitação da equipe, inexperiência profissional, insuficiência da formação e dificuldade de relacionamento interpessoal.

A liderança está presente no planejamento do cuidado. É identificada como essencial no desenvolvimento das atividades do enfermeiro, em sua relação com a equipe, usuários e familiares. Essa relação é considerada como uma das atividades mais estressantes desse profissional $\left(\mathrm{A} 9^{(22)}\right)$.

No entanto, o enfermeiro entende que, enquanto planeja, deixa de produzir, pois não está desenvolvendo uma atividade assistencial específica; porém, sem o planejamento, há dificuldade para iniciar seu trabalho $\left(A 8^{(21)}\right)$. $O$ enfermeiro preocupa-se com um planejamento em curto prazo que apresente soluções imediatas para problemas essenciais, enquanto o planejamento de médio e longo prazo não tem sido priorizado $\left(\mathrm{A} 8^{(21)}\right)$.

No desenvolvimento de suas atividades, o enfermeiro utiliza ferramentas gerenciais que servem como facilitadores no processo de relacionamento interpessoal, no estabelecimento dos vínculos e na organização das propostas. Algumas vezes, tais facilitadores são desenvolvidos e aplicados por ele de forma empírica, tornando-se uma peça fundamental e integrante do processo do cuidado.

A graduação contribui para o desenvolvimento das competências. Adotando conceitos básicos, ela serve como impulso para o primeiro contato do enfermeiro como gestor do cuidado e de serviços $\left(A 1^{(14)}\right)$. Os docentes do curso de graduação contribuem para a formação e participam da construção do conhecimento e da ligação dos saberes para o gerenciamento do cuidado, sendo esse o pilar das ações de enfermagem $\left(A 12^{(25)}\right)$.

A graduação, sem dúvida, é uma grande aliada no desenvolvimento do conhecimento e em sua aplicação na vida profissional do enfermeiro, tendo em vista as transformações do mercado de trabalho, que busca um profissional reflexivo, com tomada de decisão embasada no conhecimento e alinhada com as necessidades do serviço, oportunizando a integração da teoria com a prática e aproximando o enfermeiro da prática gerencial que é exigida desse profissional.

\section{Desafios a percorrer no âmbito da gestão em enfermagem}

Sendo a graduação um dos meios para o desenvolvimento do perfil do enfermeiro, um dos principais desafios dos docentes de graduação é eliminar a dicotomia existente entre o cuidado assistencial e o gerenciamento, já que a administração faz parte do processo de trabalho do enfermeiro. A lacuna entre 
o modelo gerencial apresentado na graduação e a exigência do mercado de trabalho também emerge como dificuldade a ser superada durante a vida acadêmica $\left(A 12^{(25)}\right)$.

Para que o gerenciamento em enfermagem deixe de ser considerado algo além da assistência ao paciente, é preciso que haja integração no tocante às questões dos cursos de graduação para estimular o desenvolvimento da competência gerencial no aluno. Deve-se buscar transformá-lo em um indivíduo crítico e reflexivo na sua prática cotidiana, porém, sem se embasar em uma atuação fragmentária, mas almejando ações no contexto do paradigma da complexidade $\left(\mathrm{A} 12^{(25)}\right)$.

Entretanto, a crítica à política de desenvolvimento de competências durante a formação do enfermeiro é a de que a melhoria que ocorre na qualificação do processo de enfermagem não surge vinculada ao cuidado ao cliente ou à capacitação de profissionais que exerçam reflexões e críticas, mas sim a interesses organizacionais em mão de obra qualificada.

A hierarquização surge como um fator que segmenta e dificulta o processo de comunicação, assim como os conflitos interpessoais, que são citados como desafios no processo de gerência do enfermeiro, pois comprometem a efetividade do cuidado $\left(A 7^{(20)}\right)$.

Ainda há um desencontro entre a formação advinda da graduação e o mercado de trabalho. As universidades têm focado o cuidado direto, a educação e o gerenciamento da assistência, enquanto que as exigências do mercado estão direcionadas a processos administrativos institucionais $\left(\mathrm{A} 2^{(15)}\right)$.

A disciplina de administração em enfermagem, disponibilizada aos discentes geralmente depois da metade do início do curso, tem o objetivo de oportunizar a esse profissional a construção do conhecimento. Incentivam-se o diálogo e a reflexão sobre o cuidado e o gerenciamento, com a intenção de romper esse paradigma, o que se torna o maior desafio para o docente da disciplina $\left(\mathrm{A} 12^{(25)}\right)$.

Diante de uma formação fragmentada e transmissional, bem como da necessidade de um profissional de enfermagem com competências para desenvolver uma gestão de sucesso, percebe-se que certamente há espaços de discussão sobre os processos gerenciais em enfermagem, com vistas a melhorar e qualificar os profissionais.

\section{CONSIDERAÇÕES FINAIS}

A gerência do cuidado é uma atribuição do enfermeiro diretamente relacionada à busca pela qualidade assistencial, aliando gerência e assistência, além de melhores condições de trabalho para os profissionais.

Com as modificações do mercado de trabalho, a qualificação dos profissionais torna-se imprescindível para a boa prática do cuidado, em que as competências gerenciais e profissionais devem convergir para o alcance do 
cuidado integral, que é o objetivo final da gerência do cuidado. Assim como há preocupação das instituições em relação às competências dos profissionais, o mercado exige trabalhadores qualificados, com destreza manual agregada às competências, ou seja, profissionais com perfil para atender às mudanças aceleradas do universo de trabalho.

Os conceitos de competência confundem-se com as ferramentas utilizadas no processo do cuidado. Liderança, comunicação tomada de decisão, entre outras, emergem para alguns autores como principais ferramentas, enquanto outros as entendem como competências. Isto se justifica pela quantidade escassa de estudos relacionados ao assunto e pela preferência da esfera assistencial à gerencial pelos profissionais.

O planejamento centrado na melhoria dos processos de enfermagem surge como aliado na atuação do enfermeiro. Instrumento utilizado para organização do tempo, auxilia na elaboração dos planos futuros e das atividades, na padronização de procedimentos e na divisão do trabalho e da equipe, o que contempla a relação entre profissionais, além de capacitar o enfermeiro para assistir integralmente o paciente, com o objetivo de alcançar metas estabelecidas pela instituição.

Os conflitos podem ter enfoque negativo no momento em que não são trabalhados como forma de crescimento individual e do grupo, sendo necessário o desenvolvimento de competências mediante a utilização de ferramentas, como liderança e comunicação, para tornar efetiva a atuação do enfermeiro.

A liderança emerge como o principal instrumento do processo de enfermagem, também entendido como gerenciamento do cuidado. Ela se faz presente em todas as atividades do enfermeiro, durante a organização do serviço, na relação com a equipe e a instituição, assim como na tomada de decisão, que, mesmo de forma inerente, ocupa lugar de extrema importância no perfil do profissional.

A comunicação, também apresentada como instrumento no processo de trabalho do enfermeiro, é citada nos artigos analisados como fundamental para o gerenciamento do cuidado. É importante por aproximar as ações da equipe e demais profissionais e articular todas as esferas do processo, além de interferir diretamente na liderança, já que também é citada como base para utilização desse instrumento.

A autonomia pode apresentar-se prejudicada, devido ao modelo gerencial imposto pelas instituições, assim como a conflitos interpessoais e problemas de relacionamentos com a equipe.

A dificuldade de articulação entre os processos assistencial e gerencial tem causado inquietações dos profissionais enfermeiros. Isso talvez se deva ao desconhecimento do gerenciamento, à hierarquização e burocratização das instituições, ou ainda, à falta de desenvolvimento de competências durante a formação, resultando na segmentação do processo de trabalho do enfermeiro 
e, desse modo, dificultando a qualificação do cuidado, que é o objetivo final do gerenciador do cuidado.

Esta revisão não exauriu, de forma alguma, a temática. No entanto, a construção deste estudo contribui para a organização de futuros estudos, fornecendo principalmente subsídios para a área da enfermagem, ao relacionar o desenvolvimento de competências com a prática da gerência do cuidado, com base na formação do enfermeiro e no conhecimento por ele adquirido.

\section{REFERÊNCIAS}

1. Montezeli JH, Peres AM, Bernardino E. Competências gerenciais requeridas de enfermeiros em um pronto-socorro. Rev Pesqui Cuid Fund. 2013 jul-set; 5(3): 245-52.

2. Timbó DBP, Gomes JA, Pessoa RW, Carneiro C. As competências para o gerenciamento eficaz: o caso da Rede de Serviços de Saúde São Gerardo. Rev Adm Saúde. 2009; 11(43): 75-82.

3. Baldassare RM, Ciampone MHT. A construção de competências para o gerenciamento em enfermagem: a percepção dos alunos do sétimo e oitavo semestres de graduação em enfermagem. Rev Adm Saúde. 2007; 9(35): 47 54.

4. Lourenção DCA, Benito GAV. Competências gerenciais na formação do enfermeiro. Rev Bras Enferm. 2010; 63(1): 91-7.

5. Ministério da Educação (BR). Conselho Nacional de Educação. Câmara de Educação Superior. Resolução CNE/CES n 3, de 07 de novembro de 2001. Institui as Diretrizes Curriculares Nacionais do Curso de Graduação em Enfermagem. Brasília (DF): Ministério da Educação e Cultura; 2001.

6. Molina AA, Miotto LB. Currículo de enfermagem: competências e habilidades para formação de docentes. Cuid Arte Enferm. 2009 jan-jun; 3(1): 79-87.

7. Erdmann AL, Backes DS, Minuzzi H. Gerência do cuidado de enfermagem pelo olhar da complexidade. Rev Bras Enferm. 2007 dez; 7(1): 1-12.

8. Souza MKB, Melo CMM. Atuação de enfermeiras nas macrofunções gestoras em saúde. Rev Enferm UERJ. 2009 abr-jun; 17(2): 198-202.

9. Santos JLG, Pestana AL, Guerrero P, Meirelles BSBH, Erdmann AL. Práticas de enfermeiros na gerência do cuidado em enfermagem: revisão integrativa. Rev Esc Enferm. 2013; 66(2): 257-63.

10. Santos MC, Bernardes A. Comunicação da equipe de enfermagem e a relação com a gerência nas instituições de saúde. Rev Gaúcha Enferm. 2012; 31(2): 359-66. 
11. Brasil. Lei $n^{\circ} 9.610$, de 19 de fevereiro de 1998. Altera, atualiza e consolida a legislação sobre direitos autorais e dá outras providências. Brasília (DF):

Casa Civil; 1998.

12. Teixeira E, Fernandes JD, Andrade AC, Silva KL, Rocha MEMO, Lima RJO. Panorama dos cursos de Graduação em Enfermagem no Brasil na década das Diretrizes Curriculares Nacionais. Rev Bras Enferm. 2013; 66(esp): 102-10.

13. Pereira AV. Relações de gênero no trabalho: reflexões a partir de imagens construídas de enfermeiras e enfermeiros. Cad Esp Feminino. 2011 jan-jun; 24(1): 49-77.

14. Rothbarth S, Wolff LDG, Peres AM. O desenvolvimento de competências gerenciais do enfermeiro na perspectiva de docentes de disciplinas de Administração aplicada à Enfermagem. Texto Contexto Enferm. 2009; 18(2): 321-9.

15. Gelbcke FL, Souza LA, Sasso GM, Nascimento E, Bulb MBC. Liderança em ambientes de cuidados críticos: reflexões e desafios à Enfermagem Brasileira. Rev Bras Enferm. 2009; 62(1): 136-9.

16. Hausmann M, Peduzzi M. Articulação entre as dimensões gerencial e assistencial do processo de trabalho do enfermeiro. Texto Contexto Enferm. 2009; 18(2); 258-65.

17. Fernandes LCL, Machado RZ, Anschau GO. Gerência de serviços de saúde: competências desenvolvidas e dificuldades encontradas na atenção básica. Ciênc Saúde Coletiva. 2009 set-out; 14(supl.1): 1541-52.

18. Vilela PF, Souza AC. Liderança: um desafio para o enfermeiro recém formado. Rev Enferm. UERJ. 2010 out-dez; 18(4): 591-7.

19. Pitthan LO, Guido LA, Linch GFC. Reflexão acerca da gerência em enfermagem: somos todos competentes. Rev Enferm UFPE. 2010; 4(1): 421-8.

20. Santos JLG, Prochnow AG, Lima SBS, Leite JL, Erdmann AL. Concepções de comunicação na Gerência de Enfermagem Hospitalar entre enfermeiros gerentes de um Hospital Universitário. Rev Esc Enferm USP. 2011; 45(4): 9539.

21. Almeida ML, Segui MLH, Maftum MA, Labronici LM, Peres AM. Instrumentos gerenciais utilizados na tomada de decisão do enfermeiro no contexto hospitalar. Texto Contexto Enferm. 2011; 20(esp): 131-7.

22. Santos JLG, Lima MADS. Gerenciamento do cuidado: ações dos enfermeiros em um serviço hospitalar de emergência. Rev Gaúcha Enferm. $2011 \mathrm{dez} ; 32(4)$ : 695-702.

23. Guedes CCP, Aguiar BGC. Discutindo e refletindo sobre a competência do Enfermeiro offshore. Rev Enferm UERJ. 2012 jan-mar; 20(1): 61-6. 
24. Okagawa FS, Bohomol E, Cunha ICKO. Competências desenvolvidas em um curso de especialização em gestão em enfermagem à distância. Acta Paul Enferm. 2013; 26(3): 238-44.

25. Caveião C, Hey AP, Montezeli JH. Administração em enfermagem: um olhar na perspectiva do pensamento complexo. Rev Enferm UFSM. 2013 janabr; 3(1): 79-85.

Recebido: 05 outubro 2017. Publicado: 11 outubro 2017

Correspondência: Patricia Treviso. E-mail: ptreviso15@gmail.com

Conflito de Interesses: os autores declararam não haver conflito de interesses.

(C) This is an Open Access article distributed under the terms of the Creative Commons Attribution License, which permits unrestricted use, distribution, and reproduction in any medium, provided the original work is properly cited 
